\title{
The perils of federalizing vaccine production
}

\author{
Sam Kazman and Henry I. Miller
}

Last year's spate of anthrax-laden letters in the United States is cause for concern, but so is one proposed government response: the move to federalize vaccine production, a recommendation contained in two independent reports released in November by the Institute of Medicine (IOM; Washington, DC) and the Gilmore Commission, the federal advisory panel on terrorism.

The IOM calls for the creation of a National Vaccine Authority that would have sweeping responsibilities, including market research, establishing of priorities, control of intellectual-property rights, the conduct of in-house research and development, and the financing of clinical trials of candidate vaccines. Similarly, the Gilmore commission recommends "the establishment of a governmentowned, contractor-operated national facility for the research, development, and production of vaccines for specified infections." Dismissing a primary role for the private sector, it argues that "direct government ownership or sponsorship is likely to be the only reasonable answer for producing vaccines" for such diseases as anthrax and smallpox.

But others (ourselves included) see things rather differently. We believe that the crisis in vaccine development and production is largely of the government's making. A former senior executive at a vaccine company encapsulates the problem: "You've got a booming demand for vaccines that people think cost only pennies, coupled with increasing regulatory burdens that cost companies millions. In short, the current shortage situation was, unfortunately, predictable."

The recent appearance of cases of inhalational anthrax in humans - the first in this country in a quarter century-coupled with the fear of further use of biological agents have fueled interest in vaccines against various exotic diseases. Moreover, the media have seized on the possibility of terrorists obtaining and using viruses such as smallpox and Ebola that are highly infectious and often lethal in unvaccinated populations.

For smallpox, the German government has bought six million doses of vaccine, and pres-

SamKazman (kazman@cei.org) is general counsel at the Competitive Enterprise Institute. Henry I. Miller (miller@hoover.stanford.edu) is a physician, molecular biologist, and fellow at the Hoover Institution. sure is mounting in the United States for widespread, or even universal, vaccination. (Routine smallpox vaccinations ceased in the United States in 1972.) Health and Human Services Secretary Tommy Thompson has promised that the government will obtain sufficient doses of the vaccine to immunize virtually every person in the country.

Federalizing vaccine production would obviously ride the political currents that are expanding government control over a host of activities that touch on national security, but the history of government manufacture of pharmaceuticals is far from encouraging.

Consider the decades of production of human growth hormone for short children by the National Pituitary Agency. This program, conducted from 1963 to 1985 under the auspices of the National Institutes of Health, was a haphazard operation. The hormone was prepared from human pituitary glands recovered from cadavers, and the absence of rigorous collection guidelines and purification procedures permitted contamination of the formulated drug with the agent that causes Creutzfeldt-Jacob disease, the human equivalent of bovine spongiform encephalopathy (BSE). As a result, several dozen recipients have died a lingering and gruesome death.

If this had been a private operation, competition and the threat of liability would have encouraged frequent updating of the drug's isolation and purification with state-of-the art technologies, and would have required rigorous adherence to government regulation. But when government is itself the manufacturer, these forces are attenuated and the backstop of government safety regulation is weakened. The nation's drug regulator, the Food and Drug Administration (Rockville, MD), is a sibling agency of the National Institutes of Health (NIH; Bethesda, MD), and their common political interests appear to have compromised vigorous oversight over the NIH's production of human growth hormone.

The recent history of the privately produced anthrax vaccine might appear to offer a counterexample, and to support more government involvement. The vaccine's producer, the Lansing, MI-based company BioPort, has experienced recurrent regulatory difficulties over issues ranging from poor quality control to lax record-keeping, and for several years its manufacturing has been suspended by regulators.

However, until late 1998, Bio-Port was not a private-sector operation at all; its facility belonged to the Michigan Department of Public Health. And many, if not all, of BioPort's problems arose when it was still state run. In other words, the anthrax vaccine's problems appear to originate not within BioPort, but rather from its pre-1998 period of government production-and from the absence of competition to make such products. History shows repeatedly that the private sector, not the government, is a superior place for pharmaceutical production.

Leaving aside BioPort's manufacturing problems, the design of the anthrax vaccine is antiquated. What we should be seeing (and encouraging) is biotechnology companies scrambling to use recombinant DNA technology and recent knowledge about the organism to make purer, safer, more effective vaccines-similar to the stampede in the 1980 s to produce improved second-generation hepatitis B vaccines.

The prospect of the government dominating drug research and development in an important health sector is a cause for concern; a federal move to take over vaccine design and production could replicate, on a far greater scale, the problems of both the current anthrax vaccine and the National Pituitary Agency's human growth hormone. Governments may be good at certain things, but they are rarely good at technological innovation. We may admire most postal employees for their steadfastness in the face of the anthrax threat, but we don't look to the US Postal Service for breakthrough communication technologies or other innovations; it didn't introduce Express Mail, after all, until years after Federal Express's breakthrough introduction of overnight mail. Do we really want a postal-service model for developing new medicines?

The proposal to federalize the vaccine industry is, at best, unnecessary; more likely, it will be dangerously counterproductive. Government can adequately address real and potential emergencies by contracting for large purchases of vaccines or by guaranteeing minimum sales. But making vaccine research, development, and production a governmentdominated enterprise would do little to advance either the safety of current vaccines or the development of new ones. Far better to remove the regulatory and other disincentives that currently make vaccine development so unattractive and uncompetitive. 